\title{
Influence of detergents on water drift in cooling towers
}

\author{
Rut Vitkovicova ${ }^{1, *}$ \\ ${ }^{1}$ CTU in Prague, FME, Department of Fluid Dynamics and Thermodynamics, Technická 4, 16607 Prague, Czech Republic
}

\begin{abstract}
An influence of detergents on the water drift from the cooling tower was experimentally investigated. For this experimental measurements was used a model cooling tower, especially an experimental aerodynamic line, which is specially designed for the measurement and monitoring of processes taking place around the eliminators of the liquid phase. The effect of different concentrations of detergent in the cooling water on the drift of water droplets from a commonly used type eliminator was observed with visualization methods.
\end{abstract}

\section{Introduction}

The research and development of wet cooling towers could be divided into three parts: Part One, which deals with the most efficient heat transfer between air and water and tries to optimize especially the function of the cooling fills and spraying nozzles as described in [1] where the author closely examines for the calculations and descriptions of processes from the viewpoint Thermodynamics [2], where the authors analyse experimental measurements of the thermal characteristics of the grid fills in the tower. The second part is the environmental issue. Cooling tower as a heat exchanger may more or less affect the environment and their activities have a negative effect on it. The formation of the plume is one of the problems and therefore it pays attention to the predictions using numerical models, as stated in [3], [4]. Great attention is also paid to drift of cooling water droplets. Eliminators of a liquid phase drift from cooling tower together with fills, nozzles and water distribution systems are essential elements of wet cooling towers. Eliminators are placed above spray nozzles on the upper floors of the tower. Their main task, as their name suggests, is to reduce the water drift of cooling water from the system. Reasons for seeking to minimize drift are both reducing the loss of cooling water from the system and also ecological reasons. Drift water may cause-consequence of adverse weather conditions a build up of ice and fog near the tower, can chemicals contaminate neighborhood which is contained in the cooling water, and ultimately may contain bacteria which live in refrigeration systems. Therefore, many countries are given the value of the maximum drift of the cooling water (approximately $0.005 \%$ of the cooling water or less).

Sufficient pure water is becoming recently an increasingly common problem in the world. Therefore it is encountered increasingly in cooling using with poor quality water. Deterioration of water quality has a significant influence on its properties and behavior. The water with reduced surface tension has a particularly negative effect on the eliminators. This occurs when the cooling water contains detergents.

\section{Principles of drift eliminators function}

Effective reduction of unpolluted water mass from air flow is mainly due to the curved channels of the eliminator. The larger is the droplet size, the larger inertia forces actuate on it in a curved channel, which leads to the fact that the droplet is no longer able to follow the flow field and adheres to the wall of the eliminator and streams down by gravity into the space of the cooling fills. The maximum droplet size, which passes through the eliminator, thus largely depends on the shape of the channel, which can be designed by CFD simulation [5]. However, if the water is contaminated with detergents, its behavior significantly changes. Due to detergents the surface tension of water decreases, which has two significant negative consequences for the effectiveness of eliminators: 1) reduces the diameter of the droplets, 2) increases the adhesion to the surface of the eliminator. As a result of these phenomena, the eliminators efficiency decreases significantly. Given that this is a new problem in a wet cooling branch, it is at first necessary for the successful solution to experimentally analyze, what processes and phenomena occur in the eliminators depending on the concentration of detergent contained in the water.

\section{Measurement}

\subsection{Experimental facilities and measurement techniques}

Visualization method was used for a monitoring of the phenomena, which occurs in the eliminators during the

* Corresponding author: rut.vitkovicova@,fs.cvut.cz 
passing of water with a deteriorated quality. This experiment was conducted in an experimental aerodynamic line specially adapted for measuring of eliminators characteristics. In Fig. 1 is a scheme of the experimental line. Below the inlet nozzle has placed a reservoir with water, which is supplied by a pump to the nozzle in the area below the test section.

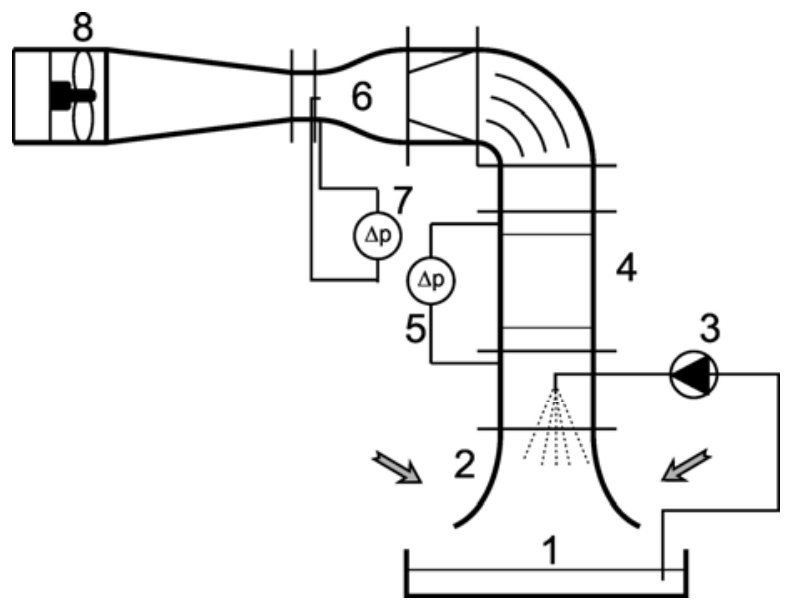

Fig. 1. The scheme of the experimental line: 1 - water reservoir, 2 - air inlet contraction, 3 - pump, 4 replaceable test section, 5 - pressure drop measurement, 6 - contraction for the mass flow rate measurement, 7 dynamic pressure measurement, 8 - driving fan

For this measurement, it was used as the spray nozzle a commonly used nozzle in cooling towers from BETE Fog Nozzle, Inc. The test section has a cross section $400 \times 400 \mathrm{~mm}$ and a height $600 \mathrm{~mm}$ and is made from transparent plexiglass, order to be able to carry out optical measurements and visualization. The indisputable advantage of this experimental line is a relatively small reservoir, which allows easy replacement of water sprayed.

A visualization based on the principle specified in [6] was chosen for a basic analysis of the behaviour of water with detergents in the eliminators. A continuous laser was used as the lighting in this case. The images were obtained by a camera Nikon D 80 with a lens with a focal length of $85 \mathrm{~mm}$. A surface tension of water with various concentrations of surfactant was determined by the method described in [7].

\subsection{Experimental set - up}

Test measurements were carried out for the blade type eliminators, which were placed in a special box (Fig.2). This box allows the optical access to the channel between the eliminators. Order to be able to monitor this area, eliminator was specially adapted, when the middle part was made from a transparent polycarbonate. This allowed to laser sheet an access to the channel at an angle of about $45^{\circ}$.

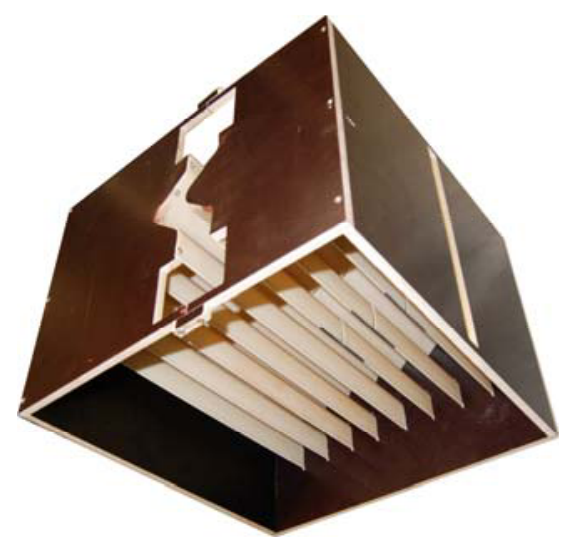

Fig. 2. The box with eliminators

It was observed 9 regimes as indicated in Table 1. For the three air velocity was watching the behavior of tap water droplets, water droplets with a detergent in a ratio of 1: 1000 and water droplets with a detergent in a ratio of $1: 500$.

Table 1. The regimes of measurement

\begin{tabular}{|c|c|c|c|}
\hline Regime & $\begin{array}{c}\text { Air } \\
\text { Velocity } \\
{[\mathbf{m} / \mathbf{s}]}\end{array}$ & Water & $\begin{array}{c}\text { Surface } \\
\text { tension } \mathbf{~} \\
{\left[\mathbf{1 0}^{-3} \mathbf{N . m}^{-1}\right]}\end{array}$ \\
\hline 1 & 3 & Tap water & 72.7 \\
\hline 2 & 4.2 & Tap water & 72.7 \\
\hline 3 & 4.8 & Tap water & 72.7 \\
\hline 4 & 3 & Detergent $1: 1000$ & 61.7 \\
\hline 5 & 4.2 & Detergent $1: 1000$ & 61.7 \\
\hline 6 & 4.8 & Detergent $1: 1000$ & 61.7 \\
\hline 7 & 3 & Detergent $1: 500$ & 53.9 \\
\hline 8 & 4.2 & Detergent $1: 500$ & 53.9 \\
\hline 9 & 4.8 & Detergent $1: 500$ & 53.9 \\
\hline
\end{tabular}

\section{Results}

The first test measurements were the measurement with clean tap water, the surface tension values reached 72.68. $10^{-3} \mathrm{~N} . \mathrm{m}^{-1}$. In this case, pure water catches on the sides of the eliminators, where it forms a water film which extends up to half of the height of the channel between the eliminators (Fig.3). From the obtained images, it is seen that the situation may arise whereby smaller droplet detached from a water film, but even that is captured in the channel of eliminator (see Fig. 4 at the end of this article). The used method of visualization enables to capture only the larger droplets trace, however, the presence of smaller droplets can detect by changes of brightness in the channel and in places just above it. It has been found from the measurement by IPI method that droplets which may pass through this 
eliminator, have a size on the order of microns to about 60 microns. [8].

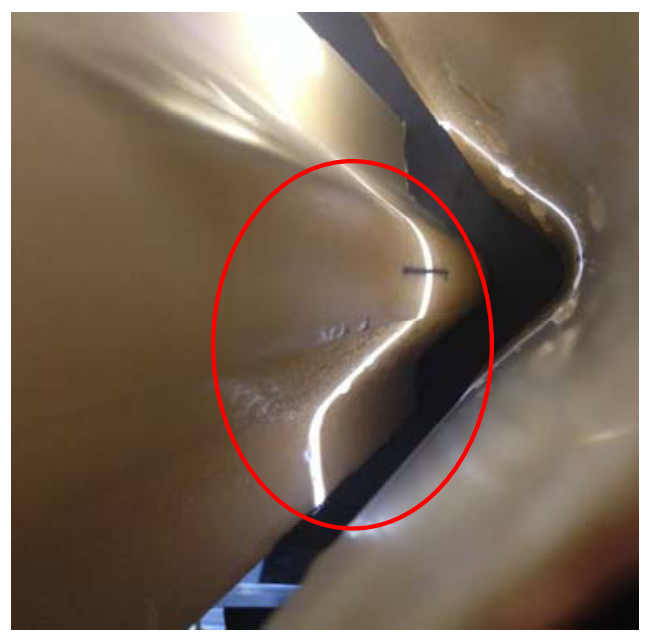

Fig. 3. The eliminators after the measuring with pure water (in the red ellipse it is shown the wet part of eliminators wall)

When increasing the velocity slightly increases the number of droplets entering into the eliminators channel, and thus slightly decreasing the efficiency of elimination (Fig. $4 \mathrm{a}-4 \mathrm{c}$ ). However, a water film did not form even at the highest measured velocity at the top of the channel.

In a second test measurement water contained detergent in a ratio of 1: 1000 and its surface tension dropped to 61.7. $10^{-3} \mathrm{~N} . \mathrm{m}^{-1}$. In this case, it was already a considerable difference in the behavior of droplets. In Figures $4 d-4 f$ are images for different inlet airflow velocities. It is apparent that the number of entering droplets increased and so has increased the number of droplets from the eliminator. It was observed on the eliminators walls the water film even in areas that were not wetted in the case of zero concentration of detergent in the water and at the same air flow velocity. This fact has one of the major impacts on the ability of the drift eliminator to capture water. When reaching a certain velocity, called the break throw velocity, it happens that the droplets will begin to detach from a water film which is then entrained in air stream out of the tower. It wasn't observed detaching of droplets from water film during measurements with clean water for a given velocity, however at the time of the second set of measurements with water with reduced surface tension, it was observed detaching of the droplets from water film at the same velocities.

The third test measuring was carried out for the concentration of detergent in water in the ratio of 1: 500, and the surface tension of this solution decreased to 53.9. $10^{-3}$ N.m ${ }^{-1}$. In this measurement, it hasn't been a substantial difference by this visualization method in passing droplets through the channel compared to the previous case. The water film is formed over the whole surface of the eliminator. Images from this measurement are shown in Figures $4 \mathrm{~g}-4 \mathrm{i}$. The more obvious difference was observed only above the eliminators, where it could see more flooding. Due to the lower surface tension, the droplet diameter decreased, therefore, a larger amount may go through eliminator.

\section{Conclusion}

This work deals with an introduction to the issue of cooling systems with using of water with deteriorated quality. There was studied the influence of changes in surface tension of water on the ability eliminators capture water droplets. The assumptions confirm on basic experimental measurements, that water with a slightly reduced surface tension is significantly worse captured using conventional eliminators. It was verified from visualizations and observations that more drops of water passing through the channel of eliminator already when the surface tension was reduced by about the 10. $10^{-3} \mathrm{~N} . \mathrm{m}^{-1}$, thus to the value $61.7 .10^{-3} \mathrm{~N} . \mathrm{m}^{-1}$. These were either captured on the wall, wherein it formed the water film or, if their size was small enough, flew out of the eliminator. Just increased the number of smaller droplets and higher wettability is due to the smaller surface tension. It was observed higher drift of water over eliminators with increasing air velocity and decreasing surface tension. To obtain detailed information, such as droplet size distribution above and below the eliminator and the overall efficiency of the eliminator relative to the water flow, it is necessary to conduct further experiments.

\section{Acknowledgements}

The author acknowledges the support received from Advanced technologies for heat and electricity production TE01020036 and the Centre of 3D volumetric anemometry - COLA, reg. č. CZ.2.16/3.1.00/21569 - Operating Program Prague competitiveness.

\section{References}

1. D.G. Kröger, Air-Cooled Heat Exchangers and Cooling Tower, (2004)

2. P. Vitkovic, L. Dvorak, HTFF, 127, (2016)

3. A. Kouchi, R. Ohba, K. Okabayashi, T. Nonaka, Mitsubishi heavy industries Ltd. technical review, Vol. 36, 3, (1999)

4. J. Cizek, J. Nozicka, AIP Conf. Proc. 1745, 020004 (2016)

5. J. Stodůlka, R. Vitkovičová, EPJ Web of Conferences, 114, 02111 (2016)

6. Pavol Vitkovic, EPJ Web of Conferences, 9202109 (2015)

7. S. V. Chichkanov, V. E. Proskurina, V. A. Myagchenkov, Butlerov Communications. 3 (9): 3335, (2002)

8. J. Cizek, L. Novakova, J. Nozicka, Reducing Liquid Phase Drift from Cooling Towers, (Gradient, Prague 2009) 


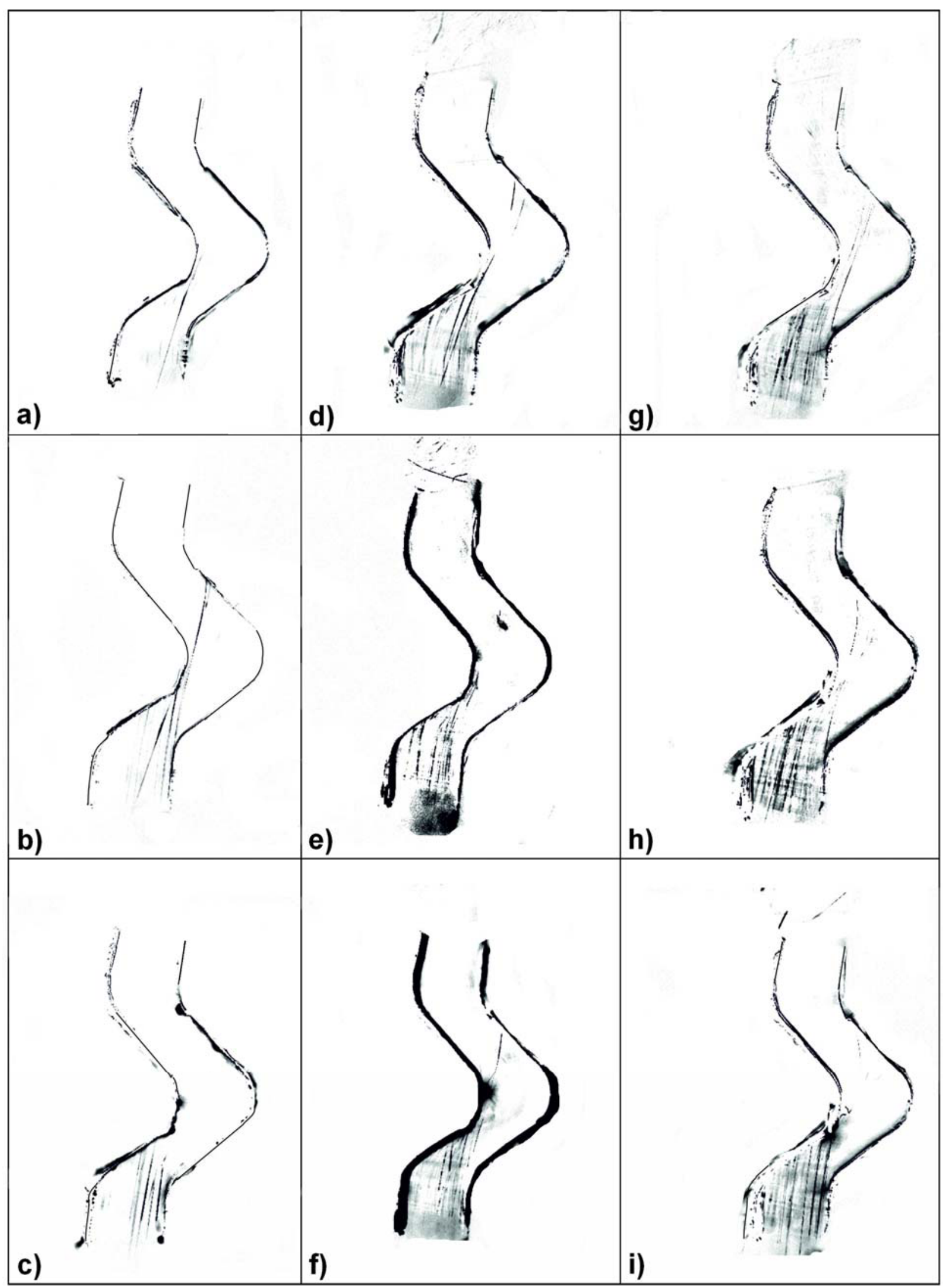

Fig. 4. Visualisations of the dependences of the surface tension on inlet velocity: a) tap water, $\sigma=72.68 .10^{-3} \mathrm{~N} \cdot \mathrm{m}^{-1}, \mathrm{v}=3 \mathrm{~m} / \mathrm{s}, \mathrm{b}$ ) tap water, $\left.\sigma=72.68 .10^{-3} \mathrm{~N} . \mathrm{m}^{-1}, \mathrm{v}=4.2 \mathrm{~m} / \mathrm{s}, \mathrm{c}\right)$ tap water, $\sigma=72.68 .10^{-3} \mathrm{~N} . \mathrm{m}^{-1}, \mathrm{v}=4.8 \mathrm{~m} / \mathrm{s}, \mathrm{d}$ ) detergent 1: $1000, \sigma=61.7$. $10^{-3} \mathrm{~N} . \mathrm{m}^{-1}, \mathrm{v}=3 \mathrm{~m} / \mathrm{s}$, e) detergent $\left.1: 1000, \sigma=61.7 .10^{-3} \mathrm{~N} \cdot \mathrm{m}^{-1}, \mathrm{v}=4.2 \mathrm{~m} / \mathrm{s}, \mathrm{f}\right)$ detergent $1: 1000, \sigma=61.7 .10^{-3} \mathrm{~N} \cdot \mathrm{m}^{-1}, \mathrm{v}=$ $4.8 \mathrm{~m} / \mathrm{s}, \mathrm{g})$ detergent 1: $\left.\left.500, \sigma=53.9 .10^{-3} \mathrm{~N} \cdot \mathrm{m}^{-1}, \mathrm{v}=3 \mathrm{~m} / \mathrm{s}, \mathrm{h}\right) \operatorname{detergent} 1: 500, \sigma=53.9 .10^{-3} \mathrm{~N} \cdot \mathrm{m}^{-1}, \mathrm{v}=4.2 \mathrm{~m} / \mathrm{s}, \mathrm{i}\right)$ detergent 1: $500, \sigma=53.9 .10^{-3} \mathrm{~N} \cdot \mathrm{m}^{-1}, \mathrm{v}=4.8 \mathrm{~m} / \mathrm{s}$ 